\title{
DESENVOLVIMENTO, PRODUTIVIDADE E QUALIDADE DE PERAS SOBRE PORTA-ENXERTOS DE MARMELEIRO E Pyrus calleryana ${ }^{1}$
}

\author{
MATEUS DA SILVEIRA PASA², JOSÉ CARLOS FACHINELLO ${ }^{3}$, JULIANO DUTRA SCHMITZ², \\ ANDRÉ LUIZ KULKAMP DE SOUZA², ÉMERSON DE FRANCESCHI ${ }^{4}$
}

RESUMO-A pera é a fruta fresca mais importada pelo Brasil, constituindo-se em importante oportunidade de mercado para os produtores. No entanto, diversos problemas ainda limitam o cultivo da pereira, como a ausência de porta-enxertos adequados. Objetivou-se com este trabalho avaliar o desenvolvimento, a produtividade e a qualidade de peras cultivares (cvs.) Carrick enxertadas sobre 'Portugal', 'MC', 'BA29', 'D’Vranja' e 'Inta 267', e a cv. Packham's Triumph enxertadas sobre 'Adam's', 'D’Angers', 'Alongado' e 'Smyrna', e Pyrus calleryana. O experimento foi realizado durante as safras de 2009 e 2010, em pomar de pereiras de sete anos, conduzido em líder central, em espaçamento de 1,0x5,0 m, localizado Centro Agropecuário da Palma, FAEM/UFPel. O delineamento experimental utilizado foi o de casualização por blocos, com três repetições por tratamento. Avaliaram-se a área da seção transversal do tronco, a eficiência produtiva, a produtividade, a produtividade acumulada, o número de frutas por planta, sólidos solúveis totais, firmeza de polpa, massa e diâmetro de fruta. Foi possível constatar que a produtividade das cvs. Carrick e Packham's Triumph é maior com os porta-enxertos de marmeleiro 'Portugal' e 'MC'; 'Adam's' e 'D'Angers', respectivamente. A produtividade e a eficiência produtiva dessas cultivares, em geral, é inversamente proporcional ao vigor induzido pelo porta-enxerto. Frutas das cvs. Carrick e Packham's Triumph acumulam maior quantidade de sólidos solúveis totais quando utilizados porta-enxertos menos vigorosos.

Termos para indexação: Pyrus sp., Cydonia oblonga, produção acumulada, controle de vigor.

\section{GROWTH, YIELD AND FRUIT QUALITY OF PEAR GRAFTED ON QUINCE ROOTSTOCKS AND Pyrus calleryana}

\begin{abstract}
Pears are the most imported fruit in Brazil, thus its cultivation may represent an important opportunity to Brazilian growers. However, there are still some problems that restrict pear production, such as the lack of adapted rootstocks. The aims of this study were to assess growth, yield and fruit quality of two pear cultivars: Carrick grafted on quinces 'Portugal', 'MC', ‘BA29', 'D’Vranja' and 'Inta 267' and Packham’s Triumph grafted on 'Adam's', 'D’Angers', 'Alongado', 'Smyrna' and Pyrus calleryana. In a completely randomized block design, with 3 replicates per treatment, a 2-year (2009-10) experiment was carried out in a 7-year old pear orchard, trained on central leader, at 1.0x5.0 m spacing, at the Centro Agropecuário da Palma, FAEM/UFPel. The assessed parameters were trunk cross sectional area, yield efficiency, yield, cumulative yield, fruit number per tree, total soluble solids, flesh firmness, fruit weight and fruit diameter. The yield of 'Carrick' and 'Packham's Triumph' was increased when quince rootstocks 'Portugal' and 'MC'; 'Adams' and 'D'Angers' were adopted, respectively. Moreover, it was found that yield and yield efficiency of both cultivars generally was inversely proportional to the vigor induced by the rootstock. Fruits of 'Carrick' and 'Packham's Triumph' cultivars accumulated higher amounts of soluble solids when grafted on dwarfing rootstocks.
\end{abstract}

Index terms: Pyrus sp., Cydonia oblonga, cumulative yield, vigor control.

${ }^{1}$ (Trabalho 039-12). Recebido em: 04-01-2012. Aceito para publicação em: 28-08-2012.

${ }^{2}$ Eng $^{\circ}$ Agr $^{\circ}$. Msc. Doutorando do PPGA, Área de Concentração em Fruticultura de Clima Temperado. Bolsista CNPq - FAEM/UFPel, Pelotas-RS-Brasil. E-mail: mateus.pasa@gmail.com; jdsagro@gmail.com; andreluizks@yahoo.com.br.

${ }^{3}$ Eng $^{\circ}$ Agr $^{\circ}$., Dr. Prof. Titular Departamento de Fitotecnia - Área de Concentração em Fruticultura de Clima Temperado. FAEM/UFPel, Pelotas-RS-Brasil. E-mail: jfachi@ufpel.tche.br.

${ }^{4}$ Graduando em Agronomia, Bolsista de iniciação científica CNPq - Fruticultura de Clima Temperado. FAEM/UFPel, Pelotas-RS-Brasil. E-mail: emersondefranceschi@gmail.com. 


\section{INTRODUÇÃO}

A pera (Pyrus communis L.) lidera as importações de frutas frescas do Brasil. Em 2009, o volume importado dessa fruta foi de aproximadamente 160 mil toneladas, representando cerca de $90 \%$ do consumo interno. Assim, é possível constatar que a pera constitui-se em uma importante oportunidade de mercado para os produtores brasileiros. No entanto, ainda existem alguns entraves que impossibilitam produções economicamente satisfatórias, como problemas com abortamento floral, manejo inadequado e desconhecimento das melhores combinações entre cultivares-copa e porta-enxerto. O desconhecimento de porta-enxertos adequados a diferentes condições de solo e de diferentes cultivares-copa é amplamente conhecido na cultura da pera (STERN; DORON, 2009).

Um dos fatores para a cultura da pereira ser pouco expandida no Brasil é a falta de informações sobre porta-enxertos ananizantes adequados, sendo os pomares existentes enxertados principalmente sobre Pyrus sp., estes que induzem vigor excessivo nas plantas enxertadas, retardando a entrada em produção. Entretanto, porta-enxertos de marmeleiro (Cydonia oblonga) podem ser utilizados para reduzir o porte e o vigor das cultivares-copa, visando ao incremento da eficiência produtiva e à produtividade. Nas principais regiões produtoras de pera no mundo, a utilização de marmeleiros como porta-enxerto incrementou a precocidade, a produtividade e a qualidade de peras europeias (JACKSON, 2003).

$\mathrm{O}$ aumento da densidade de plantio é uma importante ferramenta para aumentar a produção e a eficiência produtiva do pomar (POLICARPO et al., 2006), mas, para isto , as plantas de pereira devem ser pouco vigorosas. Além disso, a utilização de plantas com baixo porte, que iniciam a produção precocemente, é um dos pré-requisitos para obtenção de produções regulares com frutas de qualidade, além de reduzir os custos com mão de obra, principalmente nas atividades de poda e raleio. A utilização de práticas que controlem o crescimento vegetativo, como a utilização de fitorreguladores e/ou porta-enxertos que reduzam o vigor da cultivar-copa, é fundamental em pomares modernos de pereiras.

O porta-enxerto, além de controlar o crescimento vegetativo e incrementar a produtividade nas plantas enxertadas, deve manter os atributos de qualidade das frutas produzidas ou melhorá-los. Segundo Wertheim (2002), o porta-enxerto não afeta de maneira significativa os parâmetros de qualidade de frutas nas plantas enxertadas. No entanto, a união no ponto de enxertia pode limitar o movimento de água, nutrientes e hormônios para a cultivar-copa (ATKINSON et al., 2003; JACKSON, 2003), podendo resultar em alterações em sua arquitetura, balanço hormonal e crescimento de raízes (HOOIJDONK et al., 2011). Essas modificações na cultivar-copa, induzidas pelo porta-enxerto, possivelmente alteram a qualidade das frutas, conforme observado em pereira (FALLAHI; LARSEN, 1981), macieira (TOMALA et al., 2008), pessegueiro (ORAZEM et al., 2011) e cerejeira (CANTÍN et al., 2010).

Diante do exposto, objetivo -se avaliar o desenvolvimento, a produtividade e a qualidade de peras cvs. Carrick e Packham's Triumph sobre diferentes porta-enxertos.

\section{MATERIAL E MÉTODOS}

O trabalho foi conduzido nas safras de 2009 e 2010, no Centro Agropecuário da Palma, pertencente à Faculdade de Agronomia Eliseu Maciel (FAEM), Universidade Federal de Pelotas (UFPel), localizada no município de Capão do Leão-RS (3152’00”'s; 52 21'24”W; $48 \mathrm{~m}$ de altitude). O solo do campo experimental é classificado como Argissolo Amarelo eutrófico típico (SEVERO, 1999). Segundo classificação de Köeppen, a região de Pelotas apresenta clima do tipo Cfa (KUINCHTNER; BURIOL, 2001), com precipitação média anual de $1.367 \mathrm{~mm}$, temperaturas, mínima e máxima anual de $-3{ }^{\circ} \mathrm{C}$ e 39,6 ${ }^{\circ} \mathrm{C}$, respectivamente, e temperatura média anual de $17,8^{\circ} \mathrm{C}$. O acúmulo médio de temperaturas inferiores a $7,2^{\circ} \mathrm{C}$ é de 400 horas.

$\mathrm{O}$ experimento foi instalado em pomar de sete anos, plantado com espaçamento de $1 \mathrm{~m}$ entre plantas e $5 \mathrm{~m}$ entre filas, totalizando 2.000 plantas $\mathrm{ha}^{-1}$. As plantas foram tutoradas através de uma estrutura composta de arame, com três fios na linha de plantio e conduzidas em forma de líder central. O manejo foi semelhante para todos os tratamentos: a adubação foi baseada em análise de solo, crescimento de ramos do ano e produtividade esperada; arqueamento de ramos; tratamentos fitossanitários quando necessário, controle de plantas daninhas e irrigação por gotejamento.

O delineamento experimental utilizado foi o de casualização por blocos, com três repetições por tratamento, cada qual com duas plantas observadas. Foi utilizada a casualização por blocos para neutralizar os efeitos da diferença de declividade do terreno. Os tratamentos consistiram na cv. Carrick, combinada com os porta-enxertos de marmeleiro 'Portugal', 'MC', 'BA29', 'D’Vranja' e 'Inta 267', e a cv. Packham's Triumph com os porta-enxertos de marmeleiro ‘Adam's', 'D'Angers', ‘Alongado' e 
'Smyrna', e de pereira Pyrus calleryana. A enxertia foi realizada em junho de 2001, por meio de garfagem em dupla fenda, utilizando estacas de cada cultivar-copa com duas a três gemas.

As avaliações de produção foram realizadas na primeira quinzena de fevereiro de 2010 e de 2011, sendo colhidas manualmente todas as frutas das plantas. O parâmetro utilizado para definir o ponto de colheita foi a mudança da cor de fundo da película: marrom- esverdeado para 'Carrick' e amarelo-esverdeado para 'Packham's Triumph'. As frutas colhidas foram acondicionadas em caixas plásticas previamente sanitizadas e deixadas à sombra. Posteriormente, foram selecionadas amostras de quinze frutas por repetição, as quais ficaram em câmara fria $\left(0 \pm 1^{\circ} \mathrm{C}\right.$ e UR de $85 \pm 5 \%$ ) por trinta dias, para então serem realizadas as análises físico-químicas.

Avaliou-se a área da seção transversal do tronco (ASTT), calculada através das seguintes fórmulas: ASTT $=\pi \cdot r^{2}$, em que $\pi=3,1416$ e $r$ (raio) $=\mathrm{d} / 2$, em que $\mathrm{d}=$ diâmetro de tronco. $\mathrm{O}$ diâmetro do tronco foi obtido pela mensuração realizada com paquímetro digital na seção transversal (duas medidas opostas), na região localizada $5 \mathrm{~cm}$ acima do ponto de enxertia, em 12-04-2010 e 18-03-2011, expresso em milímetros (mm); eficiência produtiva (calculada através da relação: massa média de frutas por planta/ASTT - $\mathrm{kg} \mathrm{cm} \mathrm{cm}^{-2}$ ); produtividade (obtida pela multiplicação da massa média de frutas por planta, pelo número de plantas por hectare - $\mathrm{Mg} \mathrm{ha}^{-1}$ ); produtividade acumulada (obtida pela soma das produtividades de 2009 e 2010 - Mg ha-1); número de frutas por planta (valor médio da contagem das frutas das plantas observadas em cada repetição); sólidos solúveis totais (SST - expresso em ${ }^{\circ}$ Brix); firmeza de polpa (FP expressa em kgf). Estas duas últimas variáveis foram realizadas através de análise não destrutiva, com o equipamento NIR-Case (SACMI); massa de fruta (MF - obtida pela divisão da massa total da amostra pelo número de frutas e expressa em $\mathrm{kg}$ ); diâmetro de fruta (DF), obtido pela média das mensurações de cada fruta da amostra na seção transversal (duas medidas opostas) com paquímetro digital e expresso em milímetros (mm).

A análise de variância (ANOVA) foi realizada pelo teste $\mathrm{F}$ e, quando significativo, os dados foram submetidos à comparação de médias pelo teste de Duncan, ao nível de 5\% de significância. Os dados relativos ao número de frutas foram transformados através da expressão $(x+1)^{1 / 2}$, para atender ao pressuposto da homogeneidade de variância, preconizado pela ANOVA.

\section{RESULTADOS E DISCUSSÃO}

A produtividade em 2009, 2010 e acumulada, para ambas as cultivares avaliadas, foi afetada de forma significativa pelo porta-enxerto, exceto para 'Packham's Triumph' em 2009 (Figura 1). Para 'Carrick' em 2009, a maior produtividade foi observada com o marmeleiro 'Portugal', sendo este novamente superior em 2010, juntamente com 'MC' (Figura 1A). Com relação à produtividade acumulada, Portugal' foi superior a 'MC', sendo os demais inferiores a estes. Já para 'Packham's Triumph', em 2009, não houve diferenças de produtividade entre os porta-enxertos, ao passo que, em 2010, esta foi maior com 'D'Angers' e inferior com Pyrus calleryana. A produtividade acumulada foi superior com 'Adams', seguido de 'D'Angers', 'Smyrna', 'Alongado' e Pyrus calleryana (Figura 1B). A eficiência produtiva comportou-se de maneira semelhante às variáveis produtivas anteriormente descritas. A maior eficiência produtiva de 'Carrick' foi observada com 'Portugal' e 'MC' (2009 e 2010), sendo que, para 'Packham's Triumph', foi com 'Adam's (2009), este que não foi superior apenas à 'Alongado' em 2010. A redução geral na produtividade e na eficiência produtiva de 'Packham's Triumph', em 2010, possivelmente seja efeito da insuficiência de frio, pois essa cultivar necessita de $600 \mathrm{~h}$ inferiores a $7,2^{\circ} \mathrm{C}$ para superar completamente a dormência, e o acúmulo de horas de frio nesse ano foi de $348 \mathrm{~h}$, contra $445 \mathrm{~h}$ em 2009. Isso pode ter resultado em maior abortamento floral e, consequentemente, em redução na produção.

Os resultados obtidos sugerem a existência de relação entre a produtividade e o vigor induzido pelo porta-enxerto. Gjamovski e Kiprijanovski (2011), estudando a influência de nove porta-enxertos sobre a produtividade da macieira 'Granny Smith', verificaram aumento na produtividade com a redução do vigor induzido pelo porta-enxerto. Essa relação entre produtividade e vigor foi observada neste trabalho na cv. Carrick, em que os porta-enxertos 'Portugal' e 'MC' apresentaram menor ASTT (Tabela 1), e foram mais produtivos que os porta-enxertos mais vigorosos (Figura 1A); e na cv. Packham's Triumph, com o porta-enxerto ‘Adams' sendo menos vigoroso e mais produtivo. Esse efeito pode ser explicado pela redução na competição entre crescimento vegetativo e produção. De acordo com Du Plooy et al. (2002), os tecidos vegetativos competem com as frutas pelos fotoassimilados, resultando em uma relação inversa entre produção e crescimento vegetativo. Resultados semelhantes foram obtidos por Maas (2008) para as cvs. Conference e Doyenné du Comice, em que o 
porta-enxerto 'MC' esteve entre os mais produtivos. No entanto, Alonso et al. (2011) constataram que o porta-enxerto 'Adams', considerado de baixo vigor, foi o mais produtivo com 'Doyenne du Comice' e o menos produtivo com 'Conference', sugerindo a ocorrência de interação entre cultivares e porta-enxertos.

Outra hipótese para os resultados de produtividade é o efeito da incompatibilidade de enxertia entre as combinações estudadas. Essa hipótese baseia-se no fato de que os porta- enxertos menos vigorosos, que induziram maiores produtividades, tenham apresentado algum nível de incompatibilidade com a cultivar-copa, representado pelo maior diâmetro de tronco no ponto de enxertia, em relação às regiões localizadas abaixo e acima do mesmo, conforme estudos de Francescatto et al. (2010). De acordo com Ciobotari et al. (2010), a incompatibilidade de enxertia está associada com a descontinuidade dos vasos de xilema e floema, dificultando o fluxo de seiva para a cultivar-copa e, dessa forma, resultando em maior acúmulo de carboidratos na parte superior. A alteração no balanço de carboidratos na cultivar-copa está estritamente relacionada ao seu potencial produtivo.

De acordo com Gjamovski e Kiprijanovski (2011), um dos requisitos mais importantes de um porta-enxerto é sua capacidade em controlar o vigor da cultivar-copa, permitindo o adensamento de pomares. Atualmente, a tendência mundial no cultivo de pereiras é o plantio em alta densidade, principalmente pelo aumento da produtividade, melhor qualidade de frutas e rápido retorno de investimento (MAAS, 2008). Uma das condições para que esse sistema obtenha sucesso é a utilização de porta-enxertos que reduzam o vigor da cultivar-copa. Sendo assim, os porta-enxertos 'Portugal' e 'MC' para 'Carrick' e ‘Adams’ para ‘Packham's Triumph’, que mostraram maior produtividade, podem ser opções para implantação de pomares em média densidade no Brasil, mediante realização de estudos adicionais para confirmar a regularidade de produção dessas combinações.

A maior ASTT para a cv. Carrick, em 2009, foi observada com 'Inta 267' e menor com 'MC', e no ano de 2010, 'D’Vranja' e 'Inta 267' foram superiores a 'Portugal' e 'MC'. Na cv. Packham's Triumph, no ano de 2009, os maiores valores de ASTT foram obtidos pelos porta-enxertos 'Smyrna' e Pyrus calleryana, e os menores, por 'Alongado’ e 'Adams', sendo que, em 2010, Pyrus calleryana foi superior aos demais (Tabela 1 ).

De acordo com os resultados da ASTT, pode-se constatar grande variabilidade no vigor induzido pelos diferentes porta-enxertos nas duas cultivares avaliadas. Sugar et al. (2005) observaram maior diâmetro de tronco da pereira cultivar 'Comice' quando enxertada sobre Pyrus calleryana. No entanto, existem grandes diferenças no vigor induzido mesmo entre os marmeleiros, com alguns deles apresentando vigor similar aos porta-enxertos de Pyrus sp., como o porta-enxerto de marmeleiro 'Smyrna' na cv. Packham's Triumph, que apresentou ASTT similar a $P$. calleryana, este que, comprovadamente, induz alto vigor nas plantas enxertadas. Comportamento semelhante foi observado na cv. Carrick, com diferenças no vigor induzido pelos porta-enxertos de marmeleiro.

A existência de diferentes níveis de vigor induzido pelo porta-enxerto é de extrema importância para a produção de pereiras. No entanto, de acordo com Wertheim (2002), além da influência do porta-enxerto, o vigor das plantas enxertadas também é determinado pelas condições de solo, clima e cultivar-copa. Sendo assim, porta-enxertos vigorosos devem ser utilizados em solos com fertilidade natural baixa, e pouco vigorosos em solos de alta fertilidade, permitindo, desta forma, o equilíbrio vegetoprodutivo da cultivar-copa.

Resultados significativos foram obtidos para as variáveis SST e FP nas cultivares avaliadas, tanto em 2009 quanto em 2010, com exceção de SST em 'Carrick' no ano de 2010 (Tabela 2). Para essa cultivar, os marmeleiros 'MC' e 'Portugal' foram superiores aos demais na variável SST. 'Portugal’ também apresentou maior FP em 2009 e, juntamente com 'MC', em 2010. Considerando-se a cv. Packham’s Triumph, os porta-enxertos que apresentaram maiores valores de SST foram 'Alongado' e 'D’Angers', em 2009 e 2010, respectivamente. Pyrus calleryana foi inferior aos demais nessa variável, em ambos os anos de avaliação. A maior FP em 'Packham’s Triumph’, em 2009 e 2010, foi observada com 'D’Angers’ e ‘Alongado', e menor com Pyrus calleryana em 2009 e 'Smyrna' em 2010 (Tabela 2).

A variável massa de fruta foi afetada de forma significativa apenas em 2010 na cv. Carrick, sendo o menor valor observado com 'Inta 267', e em 2009 na cv. Packham's Triumph com Pyrus calleryana (Tabela 2). O diâmetro de fruta diferenciou-se apenas em 'Packham's Triumph' no ano de 2009, sendo as maiores frutas obtidas por 'D’Angers' e menores com Pyrus calleryana e 'Smyrna’. Já para a variável número de frutas por planta, resultados significativos foram observados com 'Carrick' em 2010, sendo o maior valor observado com o marmeleiro 'Portugal', seguido de 'MC', sendo os demais inferiores a estes (Tabela 2).

Segundo Wertheim (2002), parâmetros de 
qualidade das frutas de pereiras parecem ser pouco afetados pelo porta-enxerto. Foram observadas diferenças nos parâmetros de qualidade das frutas avaliadas, principalmente em SST e FP. Os maiores valores foram observados sobre os porta-enxertos menos vigorosos, ou seja, 'Portugal' e 'MC' na cv. Carrick e 'Alongado', 'D'Angers' e 'Adams' na cv. Packham's Triumph (Tabela 2). Isto indica uma possível competição entre crescimento vegetativo, induzido pelo porta-enxerto e SS nas combinações mais vigorosas, pois os fotoassimilados, possivelmente, são utilizados para o crescimento vegetativo, prioritariamente, ao acúmulo nas frutas. Além disso, porta-enxertos menos vigorosos apresentam menor volume de raízes devido à redução no transporte de auxinas da copa para as raízes, limitando seu crescimento (HOOIJDONK et al., 2011), resultando na redução de translocação de água para as frutas no momento da maturação, aumentando a concentração de SST. A FP comportou-se de maneira semelhante a SST, com tendência a ser maior nas combinações menos vigorosas. Esse efeito pode ser explicado pelo possível efeito do porta-enxerto sobre a maturação das frutas. Fallahi e Larsen (1981) observaram diferenças na maturação de peras 'Bartlett' e 'd'Anjou', porém esse efeito ocorreu em apenas um dos anos de avaliação, sugerindo interação copa x porta- enxerto x ambiente. Iglesias e Asín (2011) não encontram diferenças em SST e FP nas frutas da cv. Conference sobre diferentes porta-enxertos, apenas para massa e tamanho de frutas. Logo, estudos adicionais e mais aprofundados são necessários para elucidar o real efeito do porta-enxerto sobre a qualidade de peras e sua interação com diferentes cultivares- copa e condições ambientais.

Os resultados de massa de fruta, diâmetro de fruta e número de frutas por planta podem ser explicados, em parte, pelo vigor induzido pelo porta-enxerto. Essa hipótese está fundamentada no fato de que estas variáveis, quando significativas, de maneira geral, fo- ram inferiores com os porta-enxertos mais vigorosos, tanto em 'Carrick' quanto em 'Packham's Triumph', ou seja, com 'Inta 267' e 'Pyrus calleryana', respectivamente (Tabela 2). Esses porta-enxertos vigorosos induzem elevado crescimento vegetativo, competindo fortemente pelos fotoassimilados com as frutas. Além disso, plantas com maior crescimento vegetativo causam maior sombreamento interno da planta, reduzindo assim a fotossíntese e, consequentemente, a assimilação de carbono. De acordo com Morandi et al. (2011), a redução da disponibilidade de carbono para a planta aumenta a competição entre drenos vegetativos e produtivos e, assim, reduz a quantidade de fotoassimilados disponíveis para as frutas. Dessa forma, o uso de porta-enxertos que controlem o crescimento vegetativo das plantas é desejável, no intuito de melhorar a distribuição de fotoassimilados, nutrientes e hormônios entre os vários drenos da cultivar-copa, melhorando a qualidade das frutas obtidas. $O$ fato de ' $D$ 'Angers', que se mostrou de médio vigor, induzir maior diâmetro de frutas em 2009, juntamente com os porta-enxertos menos vigorosos, pode ser um indicativo de que o mesmo induz adequado equilíbrio vegetoprodutivo na cultivar-copa.

Os resultados obtidos indicam que existem combinações de copa x porta-enxerto com potencial para serem cultivadas no Rio Grande do Sul. No entanto, os dados obtidos referem-se apenas a dois anos de avaliação, e, dessa forma, estudos adicionais são necessários para verificar a homogeneidade dos efeitos dos porta-enxertos estudados ao longo dos anos, permitindo a indicação de porta-enxertos para o cultivo de pereiras, nas regiões com condições edafoclimáticas similares à região em que o estudo foi realizado. 

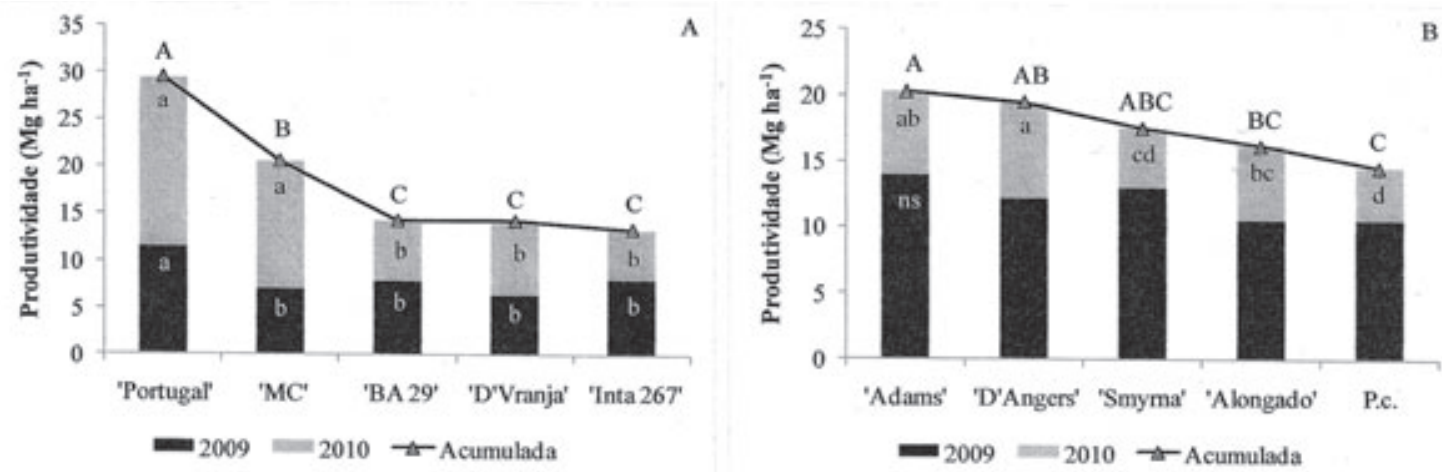

FIGURA 1- Produtividade em 2009, 2010 e acumulada das pereiras cvs. Carrick (A) e Packham's Triumph (B) sobre diferentes porta-enxertos. Pelotas, 2011. Valores seguidos de mesma letra, minúsculas nas barras e maiúsculas na linha, não diferenciam significativamente entre si, pelo teste de Duncan, a $5 \%$ de probabilidade de erro. $n s=$ não significativo pelo teste $\mathrm{F}(\mathrm{p}>0,05)$.

TABELA 1- Área da seção transversal do tronco (ASTT) e efiiência produtiva $\left(\mathrm{kg} \mathrm{cm}^{-2}\right)$ das pereiras cvs. Carrick e Packham’s Triumph sobre diferentes porta-enxertos, em 2009 e 2010.

\begin{tabular}{|c|c|c|c|c|c|}
\hline \multirow[t]{2}{*}{ Cultivar } & \multirow[t]{2}{*}{ Porta-enxerto } & \multicolumn{2}{|c|}{$\operatorname{ASTT}\left(\mathrm{cm}^{2}\right)$} & \multicolumn{2}{|c|}{$\begin{array}{l}\text { Eficiência } \\
\text { Produtiva } \\
\left(\mathrm{kg} \mathrm{cm}^{-2}\right)\end{array}$} \\
\hline & & 2009 & 2010 & 2009 & 2010 \\
\hline \multirow{5}{*}{ ‘Carrick’ } & 'Inta 267’ & 56,65 a & 69,45 a & $0,07 \mathrm{~b}$ & $0,04 \mathrm{~b}$ \\
\hline & 'D’Vranja' & $53,81 a b$ & 69,10 a & $0,06 \mathrm{~b}$ & $0,06 \mathrm{~b}$ \\
\hline & 'BA 29’ & $51,18 \mathrm{ab}$ & $61,69 a b$ & $0,08 \mathrm{~b}$ & $0,05 \mathrm{~b}$ \\
\hline & 'Portugal' & 39,43 bc & 42,82 bc & 0,15 a & $0,21 \mathrm{a}$ \\
\hline & 'MC' & 28,63 c & $39,71 \mathrm{c}$ & 0,13 a & 0,17 a \\
\hline CV (\%) & & 17,89 & 18,57 & 14,53 & 33,65 \\
\hline $\mathrm{F}$ & & 6,06 & 5,59 & 23,79 & 14,72 \\
\hline \multirow{5}{*}{$\begin{array}{l}\text { ‘Packham’s } \\
\text { Triumph’ }\end{array}$} & 'Smyrna’ & 39,19 a & $42,44 \mathrm{~b}$ & $0,17 \mathrm{~b}$ & 0,06 bc \\
\hline & P. calleryana & 46,77 a & 64,10 a & $0,12 \mathrm{~b}$ & 0,03 c \\
\hline & 'D’Angers' & $34,35 \mathrm{ab}$ & $42,62 \mathrm{~b}$ & $0,18 \mathrm{~b}$ & 0,09 bc \\
\hline & ‘Alongado’' & 22,73 bc & 27,06 bc & $0,24 \mathrm{~b}$ & $0,11 a b$ \\
\hline & ‘Adams’ & 14,88 c & 20,88 c & 0,47 a & 0,15 a \\
\hline CV (\%) & & 22,30 & 24,64 & 29,12 & 35,53 \\
\hline $\mathrm{F}$ & & 9,88 & 8,94 & 12,75 & 6,81 \\
\hline
\end{tabular}

*Valores seguidos de mesma letra na coluna não diferenciam significativamente entre si, pelo teste de Duncan, a $5 \%$ de probabilidade de erro. 
TABELA 2- Sólidos solúveis totais (SST), fimeza de polpa (FP), massa de fruta (MF), diâmetro de fruta (DF) e número de frutas por planta (NF planta-1) das pereiras cvs. Carrick e Packham’s Triumph sobre diferentes porta-enxertos, em 2009 e 2010.

\begin{tabular}{|c|c|c|c|c|c|c|c|c|c|c|}
\hline \multirow{2}{*}{ Porta-enxerto } & \multicolumn{2}{|c|}{ SST ( ${ }^{\circ}$ Brix $)$} & \multicolumn{2}{|c|}{ FP (kgf) } & \multicolumn{2}{|c|}{ MF (kg) } & \multicolumn{2}{|c|}{$\mathrm{DF}(\mathrm{mm})$} & \multicolumn{2}{|c|}{ NF planta $^{-1}$} \\
\hline & 2009 & 2010 & 2009 & 2010 & 2009 & 2010 & 2009 & 2010 & 2009 & 2010 \\
\hline & \multicolumn{10}{|c|}{ 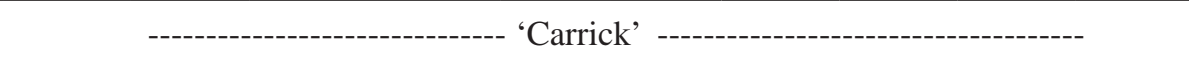 } \\
\hline 'Portugal’ & $13,68 a^{*}$ & 14,44 & 6,61 a & 6,07 a & 0,22 & $0,19 \mathrm{ab}$ & 74,7 & 68,5 & 25,2 & 46,5 a \\
\hline ‘MC’ & 13,81 a & 14,33 & 5,36 c & 6,18 a & 0,27 & $0,21 \mathrm{a}$ & 82,7 & 69,2 & 13,2 & $31,2 \mathrm{~b}$ \\
\hline ‘D’Vranja' & 12,68 b & 14,43 & $5,48 \mathrm{c}$ & $5,31 \mathrm{~b}$ & 0,25 & $0,23 \mathrm{a}$ & 78,2 & 71,6 & 13,3 & $16,8 \mathrm{c}$ \\
\hline 'BA 29’ & $12,63 \mathrm{~b}$ & 14,60 & 5,87 bc & $5,19 \mathrm{~b}$ & 0,21 & $0,22 \mathrm{a}$ & 75,8 & 72,1 & 15,2 & 14,3 c \\
\hline ‘Inta 267’ & $12,44 \mathrm{~b}$ & 13,63 & $6,43 \mathrm{ab}$ & $5,34 \mathrm{~b}$ & 0,18 & $0,17 \mathrm{~b}$ & 73,6 & 67,9 & 20,2 & 15,5 c \\
\hline CV (\%) & 2,86 & 4,32 & 6,19 & 4,86 & 21,34 & 9,42 & 6,00 & 3,43 & 26,67 & 12,41 \\
\hline $\mathrm{F}$ & 8,96 & ns & 6,9 & 8,86 & ns & 4,68 & ns & ns & ns & 13,70 \\
\hline \multicolumn{11}{|c|}{ 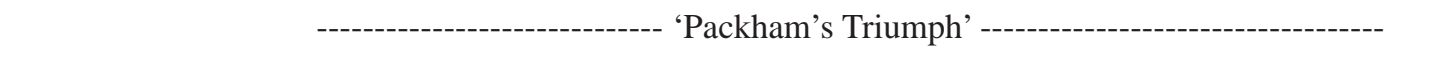 } \\
\hline 'D’Angers' & $11,70 b^{*}$ & 14,96 a & 5,81 a & 7,48 a & $0,26 \mathrm{a}$ & 0,25 & 80,7 a & 77,8 & 23,0 & 14,7 \\
\hline 'Smyrna' & 10,57 c & 13,18 bc & $5,18 \mathrm{ab}$ & $6,60 \mathrm{~b}$ & $0,22 \mathrm{bc}$ & 0,24 & $73,6 \mathrm{~b}$ & 77,1 & 24,2 & 9,2 \\
\hline ‘Alongado’ & 13,25 a & $14,06 \mathrm{ab}$ & 5,94 a & 7,41 a & $0,25 \mathrm{ab}$ & 0,22 & $77,5 \mathrm{ab}$ & 73,7 & 15,5 & 13,0 \\
\hline ‘Adams’ & $12,17 \mathrm{~b}$ & $14,12 \mathrm{ab}$ & $4,95 \mathrm{ab}$ & $6,99 \mathrm{ab}$ & $0,21 \mathrm{~cd}$ & 0,24 & $76,9 \mathrm{ab}$ & 75,4 & 28,0 & 13,7 \\
\hline P.calleryana & 10,42 c & 12,83 c & $4,48 \mathrm{~b}$ & $7,28 \mathrm{ab}$ & $0,19 \mathrm{~d}$ & 0,22 & $73,4 \mathrm{~b}$ & 74,0 & 27,7 & 15,2 \\
\hline CV (\%) & 3,74 & 3,72 & 10,40 & 5,49 & 6,96 & 13,97 & 3,08 & 3,75 & 17,23 & 14,13 \\
\hline F & 21,82 & 8,05 & 3,66 & 2,50 & 10,10 & ns & 4,95 & ns & ns & ns \\
\hline
\end{tabular}

\section{CONCLUSÕES}

1-As cultivares Carrick e Packham's Triumph apresentam maior produtividade quando enxertadas sobre os porta-enxertos de marmeleiro 'Portugal' e 'MC',e ‘Adam's' e 'D’Angers', respectivamente.

2-A produtividade e a eficiência produtiva das cvs. Carrick e Packham's Triumph, em geral, são inversamente proporcionais ao vigor induzido pelo porta-enxerto.

3-Frutas das cultivares Carrick e Packham's Triumph acumulam maior quantidade de sólidos solúveis quando utilizados porta-enxertos menos vigorosos.

\section{REFERÊNCIAS}

ALONSO, J.M.; GÓMEZ-APARISI, J.; ANSÓN, J.M.; ESPIAU, M.T.; CARRERA,. Evaluation of the $\mathrm{OH} \times \mathrm{F}$ selections as an alternative to quince rootstocks for pear: agronomical performance of 'Conference' and 'Doyenné du Comice'. Acta Horticulturae, The Hague,v.903, p.451-455, 2011.

ATKINSON, C. J.; ELSE, M. A.; TAYLOR, L.; DOVER, C. J. Root and stem hydraulic conductivity as determinants of growth potential in grafted trees of apple (Malus pumila Mill.). Journal of Experimental Botany, Lancaster, v.54, p.1.2211.229, 2003. 
CANTÍN, C. M.; PINOCHET, J.; GOGORCENA, Y.; MORENO, M. Á. Growth, yield and fruit quality of 'Van' and 'Stark Hardy Giant' sweet cherrycultivars as influenced by grafting on different rootstocks. Scientia Horticulturae, Amsterdam, v.123, p.329335, 2010.

CIOBOTARI, G.; BRINZA, M.; MORARIU, A.; GRADINARIU, G. Graft incompatibility influence on assimilating pigments and soluble sugars amount of some pear (Pyrus sativa) cultivars. Notulae Botanicae Horti Agrobotanici Cluj-Napoca, Manastur, v.38, p.187-192, 2010.

DU PLOOY, P.; JACOBS, G.; COOK, N. C. Quantification of bearing habit on the basis of lateral bud growth of seven pear cultivars grown under conditions of inadequate winter chilling in South Africa. Scientia Horticulturae, Amsterdam, v.95, p. 185-192, 2002.

FALLAHI, E.; LARSEN, F. E. Rootstock influences on 'Bartlett' and 'd'Anjou' pear fruit quality at harvest and after storage. HortScience, Alexandria, v.16, p.650-651, 1981.

FRANCESCATTO, P.; PAZZIN, D.; NETO, A. G.; FACHINELLO, J. C.; GIACOBBO, C. L. Evaluation of graft compatibility between quince rootstocks and pear scions. Acta Horticulturae, The Hague, v.872, p.253-260, 2010.

GJAMOVSKI, V.; KIPRIJANOVSKI, M. Influence of nine dwarfing apple rootstocks on vigour and productivity of apple cultivar 'Granny Smith'. Scientia Horticulturae, Amsterdam, v.129, p.742746, 2011.

HOOIJDONK, B.; WOOLLEY, D.; WARRINGTON, I. Rootstocks modify scion architecture, endogenous hormones, and root growth of newly grafted 'Royal Gala' apple trees. Journal of the American Society for Horticultural Science, Alexandria, v.136, p.93102, 2011.

IGLESIAS, I.; ASÍN, L. Agronomical performance and fruit quality of 'Conference' pear grafted on clonal quince and pear rootstocks. Acta Horticulturae, The Hague, v.903, p.439-442, 2011.

JACKSON, J.E. Biology of apples and pears. Cambridge: Cambridge University, 2003. 501p.
KUINCHTNER, A.; BURIOL, G. A. Clima do Estado do Rio Grande do Sul segundo a classificação climática de Köppen e Thornthwaite. Disciplinarum Scientia, Santa Maria, v.2, p.171-182, 2001.

MAAS, F. Evaluation of Pyrus and Quince Rootstocks for High Density Pear Orchards. Acta Horticulturae, The Hague, v.800, p.599-609, 2008.

MORANDI, B.; ZIBORDI, M.; LOSCIALE, P.; MANFRINI, L.; PIERPAOLI, E.; GRAPPADELLI, L.C. Shading decreases the growth rate of young apple fruit by reducing their phloem import. Scientia Horticulturae, Amsterdam, v.127, p.347-352, 2011.

ORAZEM, P.; STAMPAR, F.; HUDINA, M. Quality analysis of 'Redhaven' peach fruit grafted on 11 rootstocks of different genetic origin in a replant soil. Food Chemistry, Amsterdam, v.124, p.1.6911.698, 2011.

POLICARPO, M.; TALLUTO, G.; LO BIANCO, R. Vegetative and productive responses of 'Conference' and 'Williams' pear trees planted at different in row spacings. Scientia Horticulturae, Amsterdam, v.109, p.322-331, 2006.

SEVERO, C. R. S. Caracterização dos solos do centro agropecuário da Palma, UFPel, Município de Capão do Leão - RS. 1999. 97 f. Dissertação (Mestrado em Agronomia) - Faculdade de Agronomia Eliseu Maciel, Universidade Federal de Pelotas, Pelotas, 1999.

STERN, R.A; DORON, I. Performance of 'Coscia' pear (Pyrus communis) on nine rootstocks in the north of Israel. Scientia Horticulturae, Amsterdam, v.119, p.252-256, 2009.

SUGAR, D.; HILTON, R.J.; VANBUSKIRK, P.D. Effects of kaolin particle film and rootstock on tree performance and fruit quality in 'Doyenne du Comice’ pear. HortScience, Alexandria, v. 40, p.1.726-1.728, 2005.

TOMALA, K.; ANDZIAK, J.; JEZIOREK, K.; DZIUBAN, R. Influence of rootstock on the quality of 'Jonagold' apples at harvest and after storage. Journal of Fruit and Ornamental Plant Research, Mazovia, v.16, p.31-38, 2008.

WERTHEIM, S. J. Rootstocks for european pear: a review. Acta Horticulturae, The Hague, v.596, p.299-309, 2002. 